\title{
JOHN MAYNARD KEYNES BETWEEN OLD AND NEW INSTITUTIONALISM
}

\author{
Carolina Miranda Cavalcante ${ }^{*}$ \\ Emmanoel de Oliveira Boff ${ }^{\dagger}$
}

\begin{abstract}
The article considers the possible compatibility (in epistemological and ontological terms) of the conceptions of convention and institutions in the thought of John Maynard Keynes, Thorstein Veblen and Douglass North. We argue, first, that while Veblen suggests an approach to institutions based on instincts, North sustains an approach to institutions based on rational choice, which implies distinct conceptions about institutions and the social world. We then present Keynes's ontological commitments and the epistemological implications of his ontology. We conclude that there is a background ontological compatibility between Keynes and the late North in that both accept that the socioeconomic world is fundamentally uncertain and non-ergodic; also that Keynes is epistemologically closer to North than Veblen in studying the economy as a market system embedded in social institutions; and finally that Keynes's treatment of individual action is closer to Veblen's than North's, in that both Keynes and Veblen see human action as based on instincts and not only on rationality.
\end{abstract}

Keywords: Convention; Institutions; Rationality; Keynesianism, Institutionalism.

JEL Classification: B15; B25; E12.

\footnotetext{
* Professora de Economia Política da Faculdade Nacional de Direito da Universidade Federal do Rio de Janeiro (UFRJ). Contato: cmcavalcante@gmail.com

† Professor Adjunto da Faculdade de Economia da Universidade Federal Fluminense (UFF). Contato: emmanoelb@gmail.com
} 


\section{Introduction}

This article aims to present an analysis of Keynes's overall worldview and theories so as to check the extent to which they can be made compatible with the works of Veblen and North and with the institutionalist tradition more generally. Although there have been studies regarding the relation of complementarity or compatibility between Keynes and the institutional tradition - see Mouhammed (1999), Peterson (1977), Wray (2007), Thabet (2008), DesRoches and Rutherford (2008) -, no investigation has specifically focused on the ontological and epistemological compatibility between Keynes and institutionalists. We believe this investigation is relevant because it can shed some light on both the entities these traditions are committed to and on the extent to which we can have justified true beliefs about such entities. The investigation of an ontological and epistemological compatibility of the economics of Keynes and the institutional tradition can be of use for forging a theory of Keynesian Institutionalism, something that has been hinted at by Keller (1983) and sketched by Whalen (2012) after the 2008 crisis. Their contributions, however, do not make a clear distinction between old and new institutionalism and do not investigate the possibility of building a well-founded research program with compatible ontologies and epistemologies. Our paper seeks to contribute in the direction of finding a common ground for the economics of Keynes and that of the different strands of institutionalists.

Our argument will be presented in three sections. In the first section the debate within Institutional Economics will be briefly outlined. Special attention will be given to Veblen and North theoretical proposals. It is argued that while Veblen suggests an instinct-institutions approach, North sustains a rationality-institutions approach. The second section will delineate Keynes's general philosophical stance, his ontological commitments regarding the social world (with a focus on the economy), and the epistemological implications of his ontology. We will then be ready to go to section three of the article, which will furnish both a framework highlighting the importance of institutions in Keynes's thought through his notion of convention, and his conception of the decision-making process. We will then compare Veblen, Keynes and North regarding individual action in the social world, concluding that their notions of efficiency, institutions and uncertainty are influenced by their underlying epistemological and ontological views.

\section{Institutional economics: old and new}

\subsection{Veblen and the old institutionalism perspective}


Thorstein Veblen was a fierce critic of teleology, taxonomy and hedonism, suggesting a theory that pictured the social world as inhabited by human beings driven by instincts and engendering habits of thought or institutions, through their social actions. These habits (or ways of thinking and doing things), evolve through time alongside with instincts in a complex interaction:

Any community may be viewed as an industrial or economic mechanism, the structure of which is made up of what is called its economic institutions. These institutions are habitual methods of carrying on the life process of the community in contact with the material environment in which it lives (Veblen, 1899, p. 89, our emphasis).

Moreover, Veblen sustains that the drive to human action are instincts and not rationality. Thus, human beings will strive for survival, making efforts to understand the surrounding reality, to protect the group, and to build useful tools to handle the environment. According to Barnett (2017a), Veblenian instincts are of two types: simple instincts (like hunger, anger, gregariousness, nutrition, sex etc.) and complex instincts (like the workmanship, parental bent, idle curiosity, play and beauty instincts). Whereas the former are:

(...) closer to tropismatic sensibilities or involuntary behavioral urges (...) complex instincts are much more extensive complications of organic stimuli that include various basic instincts, which have been grouped together to serve a common higher-order or emergent function (Barnett, 2017a).

In other words, instincts are drives to human action, but it is the coevolution of simple and complex instincts in time that will produce institutions. These institutions, for their turn, will open up specific possibilities by which individuals can feed themselves, protect the group, construct theories about reality and build instruments to cope with the environment. As our comparison of Veblen and Keynes in the third section will try to show, the evolutionary character of institutions does not allow us to make predictions about the form these institutions will take in the future. In other words, it seems reasonable to suppose that the process of selection, mutation and replication of institutions is strongly uncertain - just like Keynes's socioeconomic world is. 
In Veblen's sense, humans do not simply make rational calculations observing institutional constraints (like North thinks); their behavior is rather guided and deeply embedded in habits of thought:

\begin{abstract}
Habits of thought with respect to the expression of life in any given direction unavoidably affect the habitual view of what is good and right in life in other directions also. In the organic complex of habits of thought which make up the substance of an individual's conscious life the economic interest does not lie isolated and distinct from all other interests (Veblen, 1899, p. 54).
\end{abstract}

In Veblen's conception, there is no dichotomy between economic life and social and moral life; all human evaluations depend on what is socially considered as the prevalent habits of thought. Thus, individual evaluation of beauty does not rely on inner conceptions about what is intrinsically beautiful, but in a social conception of beauty, much like Keynes presents in his "beauty contest" in chapter 12 of the General Theory (GT). Social evaluations are inherently connected to human practices and are usually related to social appropriateness, acceptance and belonging. Sometimes they can be more powerful in guiding human behavior than instincts as the idea of reputability in the next quote makes clear:

So far as a person, in forming a judgment of taste, takes thought and reflects that the object of beauty under consideration (...) the judgment is not a bona fide judgment of taste (...). The connection which is here insisted on between the reputability and the apprehended beauty of objects lies through the effect which the fact of reputability has upon the valuer's habits of thought (Veblen, 1899, p. 69).

Social reputability then mediates between the apprehended beauty of objects and the valuer's habits of thought. This example shows that the space for a purely rational, calculative valuation is limited by the institutions of society - in other words, by habits that tell us what is or is not reputable. We can summarize Veblen's approach to Economic Science as properly transdisciplinary - that is, it is a holistic type of knowledge whose foundation cannot be reduced to that of any separate social science. This knowledge is "concerned with the unity of intellectual frameworks beyond the disciplinary perspectives", as Stember (1991, p. 4) explains. This Veblenian instinct-institutions approach will be replaced for a rationalityinstitutions approach in New Institutional Economics (NIE), as we shall see in North's conceptual framework that follows. 


\subsection{Douglass North and new institutionalism}

There are multiple lines of research in NIE. Rutherford (1996) and Hodgson (1993) list some of them, like property rights, common law, public choice processes, organizations, agency theory, transaction costs and game theory. Despite all this diversity, Rutherford (1996) points to some defining aspects of the NIE: formalism, individualism, reductionism, anti-interventionism and the adoption of a rationality principle. Coase (1937) and Williamson (1985) were concerned with the theory of the firm and transaction costs, while North (1990) mixed many of these issues in an institutionalist theory of economic performance at a macroeconomic level. NIE also embraces a game theoretic approach and a so-called Austrian wing, comprising authors like Hayek, Nelson and Winter, and Langlois. The distinctive aspect that separates the Old Institutional Economics (OIE) from the NIE is the adherence of the latter to the marginalist approach (including the Austrians) and/or neoclassical theory. Our interest in North (1990) is precisely in that he adopts a more macroeconomic perspective, like Keynes does. North adds, however, theoretical issues left behind by post-war neoclassical theory, namely history and institutions. The inclusion of historical time and institutions within a neoclassical approach was made possible with the modification of the rationality principle. According to North (1993), in a world of incomplete information and limited computational capacity bounded rationality - individuals develop norms and rules to structure exchange. Furthermore, as society becomes larger, with more impersonal and sporadic transactions, problems of trust and compliance emerge. In small groups with repeated transactions cooperation emerges as a rational response of the individual that intends to keep doing business in the market. In large groups, with non-repeated transactions, cooperation is related to coercive formal rules.

North (1990) provides another explanation to rule-following behavior using our inner moral conceptions about what is right and what is wrong, which he called ideology. The author deploys an interdisciplinary approach to enrich his institutional theory, moving in areas of knowledge such as Economic History, Sociology, Cognitive Science and Political Science. However, this interdisciplinarity consists in applying the theory of choice to other fields of social thought - that is why his work 
is not transdisciplinary as that of Veblen. As Stember (1991, p. 4) puts it, interdisciplinarity presupposes an "integration of the contributions of several disciplines to a problem or issue [which] is required" - but the theory of rational choice remains as the foundation of North's theory. Since the 1970s, North recognizes the need to go beyond neoclassical boundaries, but using the principle of rational choice. North (1990, p. 5) states that defining "institutions as the constraints that human beings impose on themselves makes the definition complementary to the choice theoretic approach of neoclassical economic theory". Some years later, the author reaffirms his position: "Economics is a theory of choice - so far so good. But the discipline neglects to explore the context within which choice occurs. We choose among alternatives that are themselves constructions of the human mind" (North, 2005, p.11).

According to North (2005), the key to human evolutionary change is the intentionality of the players - individuals and organizations. But intentionality stems from individual perceptions, molded in beliefs and sometimes also in preferences. Beliefs are theories individuals devise about the consequences of their actions; they "are both a positive model of the way the system works and a normative model of how it should work" (North, 2005, p.2). Those beliefs arise from individual experience and past generations' experience.

Unlike Veblen (1899), North (2005) suggests that there is a gap between beliefs and reality. From an ontological point of view, North is arguably committed to a cartesian view of reality, where beliefs inside individuals' minds may or may not correspond to the reality outside. This non-coincidence between reality and beliefs is the origin of uncertainty. Therefore, North (2005) states that institutions are the structures humans impose on themselves to manage their environment and reduce uncertainty. Individuals develop formal and informal rules and beliefs to complement their limited computational capacity. Where rational behavior is not able to work properly, rules and beliefs take place to guide human action and choice. It means that choice is not always guided by a calculative rationality, since individuals may decide based on their own beliefs, on a shared culture and traditions 
and/or on laws and constitutions. They are the scaffolds humans impose on themselves to order their social and natural environments.

In synthesis, in North's conception, institutions are: (i) constraints to human action; (ii) structures of incentives to players (individuals and organizations); (iii) rules of the game (formal and informal ones). Organizations are groups of individuals gathered together with a common purpose. Organizations act as players, but they are not intentionally driven like individuals; the organizational process of decision making involves internal rules, procedures and hierarchies. Individuals are rationally limited players that also have beliefs; they develop ideologies and are capable of learning. Institutions are outside the human mind and are part of the social environment. Mental models (beliefs, ideologies, knowledge) are representations inside the human mind. Nonetheless, there is a gap between reality itself and human beliefs, intentions and human-made rules (institutions). In this sense, a failure to implement governmental policies at a macro level may be due to the gap between what the world really is and the institutional framework humans develop to cope with their limited capacity to process information with their mental models.

\subsection{Summary}

Let us briefly summarize what we found regarding the ontological and epistemological commitments of Veblen and North.

Veblen is not committed to a dualistic ontology - his "habits of thought" are not reducible to mental representations of reality; they are closely interrelated to processual and habitual ways of doing things. These habits of thought also evolve in time in an evolutionary fashion, producing unpredictable results. As a result, his epistemology is transdisciplinary - he creates an altogether new theory out of the contributions from American pragmatist philosophy and Darwinian evolutionary theory.

North is arguably committed to a cartesian ontology that separates human subjective beliefs from their enactment in the objective world. Because of this separation (which creates strong uncertainty, according to North), institutions are created to constrain, structure and provide rules for rational, maximizing action. 
Because the building of institutions takes into account the environment in which rational actions take place, North's endeavor must be interdisciplinary. In other words, he must coherently integrate findings of other social sciences into the economic theory of choice.

\section{Keynes' ontological and epistemological commitments: from uncertainty to the world as an "organic unity"}

\subsection{Roots of Keynes's thought and his modification of Marshall's approach}

It is no news that Keynes hoped, with his GT, to elaborate a new way of investigating and tackling economic problems. This new way of doing economics was fundamentally embedded, as Skidelski (2005) recounts, on a philosophy indebted to G. E. Moore and the type of social philosophy and economics developed by Alfred Marshall. This means that Keynes's view of economics was developed both within a non-utilitarian and realist ethical framework which aimed to reach for the Good - here understood as states of affairs in the world that could cause in us good "states of consciousness", such as the development of friendships and personal relations ("the pleasures of human intercourse"), the enjoyment of beautiful objects and the pursuit of knowledge. Economics, within this perspective, can be seen as the science which supplements ethics in that it helps explain how the necessary means for a better, more secure life are created, distributed and consumed, in terms of efficacy and efficiency.

In the English liberal tradition of the nineteenth century, it was usually assumed that the non-centralized decisions of self-interested agents operating in a competitive market would roughly provide the means to a better material life in an efficient way. However, the events starting with the First World War (1914-1918) showed that it is not in any social environment that self-interest can be taken as a "moving force of a great part of the motives" behind people's "individual and social action", as Marshall put in his Principles (1890). A situation of long war and deep economic crisis turns the scales to other sorts of moving forces which may not be so amenable to "the outcome of a weighted average of quantitative benefits multiplied by quantitative probabilities" as Keynes (1936, p.81) would describe it in the GT, commenting 
exactly on the influence of "animal spirits" on our decision-making. When the social environment is such that we are not sure either of the quantitative benefits or the quantitative probabilities of our actions, decision-making has to be based on other factors other than rational calculation. A situation of depression or of war may turn fear of violent death or fear of the future into one of the main moving forces propelling people's individual and social action. In such a situation, a sort of a Hobbesian state of nature may be prevalent, leading to a social organization not based on the self-interest of agents but on the order brought about by an autocratic leader. Skidelski (2010, p. 3) points out that Keynes wrote to an American correspondent in 1940 that "[f]or the first time in more than two centuries Hobbes has more to tell us than Locke". Our ability to calculate our benefits and costs in the future is severely constrained by a strongly uncertain world ruled by authoritarian leaders.

\subsection{Ontological and epistemological consequences of Keynes}

There are two consequences of the events triggered by the First World War on Keynes's ontological commitments. First, when fundamental uncertainty is essentially present in the socioeconomic world, economic action could not be studied solely as based on the calculus of self-interest.

Second, the fundamental uncertainty of the world is also related to a characteristic of human driving motives to action. A strongly uncertain world means that the study of the economy could not prescind from an investigation, or at least the acknowledgement, of human motivations other than those amenable to calculation. If the future is fundamentally uncertain, then a rational decision could not be based on only one distribution of probability function of the events in the world. This fact brings us back to Keynes's central problem in his 1921 book, the Treatise on Probability (TP): how do we relate different sets of propositions when there is no unique way to argue demonstratively from one set to the other?

The situation is such that rationality alone cannot give us the solution to the decision problem. The state of affairs in the current world cannot be described by dint of "systematic reasoning and analysis" alone, as Marshall would have it. It is as 
if our reasoning and analysis would have to be made on the basis of multiple descriptions of the state of affairs in the world (our first set of propositions) and its future tendencies (our second set of propositions). How can we be sure that the first set leads necessarily to the second set of propositions? Only by making economics a science "of thinking in terms of models joined to the art of choosing models which are relevant", to quote Keynes in his letter to Roy Harrod in July of 1938. In such a situation, Keynes would have to modify the part of the Marshallian doctrine that allowed for "measurable motives" and "systematic analysis" in the separate science of economics. The idea that the world consisted in a totality (of which the economy was but a part), already established in Marshall's Hegelian-inspired evolutionary social philosophy, would have to be modified to make economics more open to psychological, social and institutional factors. From an epistemological point of view, this means that Keynes would have to decide to make economics either a more interdisciplinary science (like North) or transdisciplinary one (like Veblen).

There is no doubt that Keynes's uncertainty permeates both the world and the process of decision-making of individuals, and this fact casts doubts on the status of economics as a separate science. It is true that (i) if the reason of self-interest leads our actions together with (ii) a price mechanism (so that we could reasonably calculate costs and benefits of our decisions), then (iii) we could deploy an economic theory that is separate from other social sciences, in that it is solely based on rational and maximizing behavior, as a good proxy to understanding the conditions of equilibrium in competitive markets. In terms of the "classical" doctrine, the optimizing decisions of a multitude of individual rational agents leads to an aggregate that is also optimal. There is no opposition between the individualwelfare associated with individual actions and the aggregate welfare of society. But, as is well known, Keynes's goal in the GT was to demonstrate that the argument which links the two propositions above does not have enough weight, due to the fact that the economy is akin to what we nowadays call a complex system. As a result, there is strong uncertainty both in the world and in people's decisions. Borrowing from G.E. Moore (1903), the "principle of organic unity" appears in Keynes's writings to show that the whole is different from the sum of its parts -- and thinking otherwise amounts to 
committing the "fallacy of composition" (Cardoso and Lima, 2008). Does this ontological commitment lead necessarily to an epistemology which breaks down the barriers between economics and other social sciences (as Veblen does)? We believe the answer to this question is negative and the idea of convention is a key factor to understand why.

Davis (1997) presents the idea of convention as central to the mature Keynes and that conventions depended not any longer on an atomistic process of decisionmaking but on an "structure of interdependent judgements". Besides that, Rotheim (1989) himself makes an interesting observation regarding the essay on Edgeworth`s obituary (1926) by Keynes. In it, Keynes mentions "organic unity" as related to "psychics", that is, to the measurement of utility or ethical value, belief or probability. Rotheim (1989), however, implies that Keynes is not talking only about the human mind, but also about "the application of quasi-mathematical methods to the social sciences". In other words, Keynes is talking about the application of mathematical methods to sciences that investigate social reality as an organic complex.

In sum, as in the case of strong uncertainty, the concept of organic unity can be applied both to the individual mind and to the world. As regards the individual mind, recent papers by Vincent Barnett $(2015$, 2017b) point out the fact that the process of decision making in Keynes cannot be made purely on a rational basis, but must take into consideration intuition (as a form of an innate unconscious reasoning), instincts (as forms of innate or learnt tendencies or impulses that resulted from processes of natural selection) and also animal spirits (as part of the "emotional cognitive system" inherited evolutionarily by humans, which helps us choose different courses of action in an uncertain world). As a consequence, the human mind in Keynes's view has an organic unity with a "cognitive architecture" (composed of rationality, intuition, instincts and animal spirits) which has developed in historical time due to processes of Darwinian evolution. One should remark that it is the interaction of the four components above which could explain human action, so that the mind should be seen as a unity. And, for the purpose of this paper, it is of utmost importance to know how these components will interact depending on the degree 
of uncertainty in the environment and in our ability to make choices based on costbenefit analysis. As long as there is a process of social and cognitive "scaffolding" which diminishes uncertainty in the environment, we can choose courses of action which are more or less amenable to calculation. As we will show in the next section, this social and cognitive scaffolding and its formation in an evolutionary process can be linked to what Keynes terms "useful mental habits".

\subsection{Summary}

Let us again try to summarize what we found concerning Keynes's ontological and epistemological commitments. First of all, ontologically Keynes introduces the issue of fundamental uncertainty and the principle of organic unity in the socioeconomic world and also in his theory. This means that the boundaries Marshall (and his father, J. N. Keynes) had drawn for economic science as separate and based on self-interested behavior had to change.

Secondly, from an epistemological point of view, does that make Keynes's economics a transdisciplinary or interdisciplinary project for a science of economics? One can tentatively say that Keynes's endeavor stands midway between North and Veblen: it is perhaps ontologically closer to Veblen but epistemologically closer to North. The next section will show how.

\section{Keynes and the institutionalism of Veblen and North: what compatibility?}

Based on the building blocks of Keynes's ontology - fundamental uncertainty and the principle of organic unity -, is there a reasonable link that one can make between Keynes and the institutionalism of Veblen and North? The natural point of entrance for our discussion are conventions, which Keynes associates with a method of making decisions in financial markets permeated by strong uncertainty. For Dequech (2011), a Keynesian convention is a kind of institution fundamental to understanding Keynes's analysis of decision not only in financial but in bonds, investment and goods markets. As Keynes (1936, p.77) states at the beginning of section 4 in chapter 12 of the GT, "the essence of this convention (...) lies in assuming that the existing state of affairs will continue indefinitely, except insofar as we have 
specific reasons to expect a change". How are these conventions formed and what is their relation to uncertainty and the principle of organic unity of the world? How can they be interpreted in Keynes's writings?

As we said before, Davis (1997) associates conventions with Keynes's mature ideas, suggesting they are a "structure of interdependent judgments". It is possible to interpret Keynes's notion of convention along these lines and his concept of weight of the argument in his TP as a measure of how strong the convention about the expected price of an asset or the expected interest rate is (in the GT). It is also possible to interpret Keynes's reluctance in using econometrics or formal mathematical models at a macroeconomic level as due to the nature of social reality: different from brute facts (whose existence is independent of our intentionality), social facts, like conventions, crucially depend on our collective intentionality: for example, money exists as such only insofar as a collective shares representations about its power as a medium of exchange, as a unit of account and as a store of value.

Let us now compare how Keynes, Veblen and North see the relation between individual action and institutions, how they understand efficient action, and their concerns about the uncertainty of the world in order to discuss the possibility of a latent institutionalism in Keynes.

First of all, it is important to understand how Veblen, Keynes and North see the relations between individual action (involving their commitments about human nature) and institutions (the set of rules shared by people when they interact). Veblen departs from the marginalist conception of rational individuals, suggesting a framework in which human instincts are the moving force that draws individuals away from inertia and impels them to action. Since the moving force to human action are instincts, the process of decision making goes through a complex network of habits of thought, or institutions. North asserts that individuals are rational, but due to the fact that this rationality is not perfect, institutions become fundamental categories of the social world. Institutions are the rules of the game that provide an incentive structure and are uncertainty-reducing mechanisms. Actual institutional frameworks are the result of the decisions individuals made in the past, which led to path-dependent economic trajectories. 
In Keynes's conception about human nature, both the Veblenian instinctinstitution framework and North's conception of rationality-institution are contemplated. Keynes considers that human action is informed by four moving mechanisms: instincts, intuition, rationality and animal spirits. In this sense, conventions arise in situations of high uncertainty in which the economic calculus is extremely difficult or even impossible. The average opinion and the standard deviation about the expected future price of an asset or the rate of interest are distinct for agents in the market. The weight of each argument is closer to zero, reflecting the ignorance that agents have about the status (or value) of the object in question ${ }^{1}$. As a result, the little weight attributed to the evidence at our disposal prompts us to resort to intuition, instincts and animal spirits in order to make a decision about the future. In such a situation, our calculations are of limited use because their weight is close to zero.

The understanding of efficient action composes the second point to highlight. In traditional neoclassical economics efficiency is usually defined in terms of Paretoefficiency. The first theorem of welfare economics shows that a perfectly competitive market leads to an allocation of factors of production and distribution of outcomes which is Pareto-efficient. The three authors compared here criticize this view, but from different perspectives.

Veblen does not provide, within the analyzed literature, a conception of economic efficiency, but we may find a conception about what the criteria to an efficient social action is. The emulative behavior is based on conceptions about the socially accepted ideas of what is good, beautiful and appropriate. This evaluation considers the habits of thought of the higher social classes. Thus, to be socially accepted and admired, individuals must behave according to the habits of thought defined as the good and right ones. As one can see, this view is as far from the neoclassical view of efficiency as possible.

\footnotetext{
${ }^{1}$ Keynes says that the weight of the argument in chapter 6 of the TP can be understood as $\mathrm{w}=\mathrm{V}(\mathrm{x} / \mathrm{h})$ $=\mathrm{Kr} /(\mathrm{Kr}+\mathrm{Ir})$, that is the amount of relevant knowledge $(\mathrm{Kr})$ in relation to the relevant knowledge $(\mathrm{Kr})$ plus relevant ignorance (Ir) about the fact $\mathrm{x}$, given the hypothesis $\mathrm{h}$ about that fact $\mathrm{x}$. It is easy to see that $\mathrm{w}$ tends to zero when we are ignorant about a fact and tends to unity as we approach certainty. See Runde (1990).
} 
North moves from a Paretian conception about efficiency - allocative efficiency - to the idea of adaptive efficiency, which "entails a set of institutions that readily adapt to the shocks, disturbances, and ubiquitous uncertainty that characterizes every society over time" (North, 2005, p. 78). Finally, North (2005) defines efficiency as the situation in which, given the technology and the information costs, the market has the lowest transaction and production costs available.

While Veblen's view of efficiency stresses social patterns of acceptance, North focuses on the idea of efficiency related to market results. The main goal of Keynes at the GT was closer to North's idea of efficiency than Veblen's one. By inserting uncertainty into the socioeconomic world, Keynes at the same time considers how humans handle this uncertainty. So, the possibility of efficiency in the economy is related to the extent to which agents in real markets (motivated not only by maximizing rationality) can grapple with the uncertainty of the world. What Keynes wants to show right at the beginning of the GT is that the model of the market economy developed by the "classics" is just a limiting case. In other words, Keynes seems to accept the results of classical economics if the environment were characterized by risk and not fundamental uncertainty. In his general case, however, the optimizing behavior of individuals is not enough to generate an optimal allocation of resources for the whole economy. In other words, in an environment in which strong uncertainty is prevalent, people's behavior is not fully amenable to rational calculation and Pareto efficient outcomes are not common. As a consequence, the economy usually ends up wasting resources and possibilities of improvement of the life of the population in the direction of the Good.

Our third point concerns the relation between uncertainty and ergodicity. Our three authors would agree that the social world is pervaded by strong uncertainty and might be classified as non-ergodic (even though neither Keynes nor Veblen used the term). Veblen and Keynes refuse predetermined laws of movement that could produce theoretical predictions about future economic outcomes because of this uncertainty. As Mouhammed (1999) remarked, the concept of strong uncertainty in Keynes (also present in the late North) can be associated with the Veblenian concept of the economy as a complex evolutionary process of selection, mutation and 
replication of institutions. This process does not have a definite end, be it a Paretoefficient allocation of resources, or the Keynesian Good or the creation of surplus value. It is, in Veblen's parlance, non-teleological. In other words, its results in the future are also not amenable to a precise calculation because the complex evolutionary process only gives us rules for the selection, replication and mutation of institutions, not telling us what the finality of the process is in itself. Even if our three authors do not embrace the same ontological perspective concerning uncertainty, the idea of social evolution as non-teleological is common to Veblen, Keynes and the late North. That is why we may have epistemological similarities between Keynes and the late North regarding the use of similar theoretical terms regarding the operation of markets. However, this apparent similarity has distinct ontological implications: an ontological proximity between Keynes and Veblen is related to an understanding of the social world as pervaded by uncertainty that cannot be completely reduced to risk.

Finally, the fourth topic refers to the possibility of finding a latent institutionalism in Keynes and identifying its type - old or new. Following the authors mentioned in the Introduction, this paper claims that there is, in fact, a latent institutionalism in Keynes which combines epistemological elements of the Northian approach and ontological elements of the Veblenian approach. Let us first present some evidence of Keynes's institutionalism and then explain the peculiarities of the combination of different elements in Keynes's ideas about institutions.

First of all, there is a lot of textual evidence that suggests that there is a latent institutionalism in Keynes. The core of the GT - parts III (the propensity to consume) and IV (the inducement to invest) - are full of references to "institutions", "conventions", "organizations", "(social) habits" and "social practice", for example, when he explains the subjective and objective factors in the propensity to consume. It is interesting to notice that he rarely uses the word "preference" or "decisions" regarding consumption; "preference" is usually attached to liquidity in the GT. In other words, Keynes is not talking about a formal theory of consumption as choice in the lines suggested by Lionel Robbins in his 1932 Essay, but specifically of propensities and habits that make us consume in a given way in a certain time and 
place. He even mentions "ostentation" and "extravagance" as motives to consumption and that consumption depends on "habits formed by race, education, convention, religion and current morals", something that fits Veblen's theory well. The fact that our marginal propensity to consume tends to decrease with the growth of income is also due to a "psychological law", according to Keynes.

Keynes also mentions inducement to invest, not simply a "decision" or "choice" along Robbins' line. In the case of markets pervaded by uncertainty, like financial markets, Keynes insists that agents are induced to invest, or to refrain from investing, by "whim", "sentiment", "urge", "instinct", "psychological propensities", "mass psychology" and also "fear" and "hope". In regard to the determination of the rate of interest, Keynes also says its determination is "highly conventional" and is not "rooted in secure knowledge," so that the public opinion (and not simply individual decision) can change fairly rapidly. Keynes also sees liquidity as "changing from time to time and depending on social practices and institutions".

We do not have much space to develop our argument further, but the evidence above points to the fact that there is a latent institutionalism in Keynes. Our second question now is, what kind of institutionalism? Is it closer to the institutionalism of North or that of Veblen?

As we said in the second section, Keynes was influenced by Marshall's view of the economy as a complex totality embedded in society and evolving through history, in a way not dissimilar to that of Karl Polanyi, in his The Great Transformation (1944 [2000]). When Keynes introduces uncertainty the frontier between economics and the other social sciences becomes blurred. What are the ontological and epistemological consequences of this move?

From an ontological point of view, one cannot say that Keynes assumes that we are dealing only with maximizing individuals and that institutions are born out of transaction costs, asymmetric information or inconsistencies in individual choices that lead to market failures and coordination problems. As we said in our section on Keynes, his individuals are moved by instincts, intuitions and animal spirits, besides rationality. The unity of these motivations (their "cognitive architecture") changes in 
history, so that across many generations "individuals began to substitute moral and rational motive as their spring of action in place of blind instinct. They must begin to do so collectively" (Keynes apud Barnett, 2017b, p. 385).

On the other hand, the economic environment that is jointly created by collective intentionality is also changeable since economics is a moral science and its categories partially depend on our sharing common representations of the world. This makes the social world strongly uncertain, since the very categories of analysis - like liquidity, for example - partially depend on "social practices and conventions". As a result, Keynes's analyses of the economic world open up the space to jointly study the relation among: 1) the "cognitive architecture" of individuals' motives; 2) the uncertainty associated with different market structures and long-term expectations; and 3) the degree of liquidity of assets present in each market. Depending on how strong and stable the collective valuations of assets are, the uncertainty will be greater or smaller and the future expectations of agents will accordingly make more or less use of rational calculation (vis-a-vis instincts, intuition or animal spirits) $)^{2}$. In other words, the economic system tends to be structurally and endogenously unstable because it is always subject to incompatibilities between the points 1,2 and 3 above. The stability of conventions - our "structure of interdependent judgements" - gives us the strength of collective valuations on which we base our future expectations.

This interpretation brings Keynes closer to Veblen than to North concerning the ontology of individual action, both because it cannot be reduced to rationality (and hence institutions do not come exclusively from transaction costs or the like) and because the very nature of the socioeconomic world is not separated from the conceptions individuals have of it. Keynes's conventions are structures which cannot be reduced to North's rules-of-the-game view of institutions, since they are part of the games individuals play in society and the economy (and, as a consequence, conventions can lead to self-fulfilling prophecies).

\footnotetext{
${ }^{2}$ So that animal spirits are partially endogenously determined by the characteristics of the market (its degree of uncertainty and the liquidity of its assets). See Setterfield (1999: 481-2). We thank an anonymous referee for drawing our attention to this point.
} 
However, in epistemological terms one can say that Keynes is closer to North. By this, we mean that his approach is more interdisciplinary than transdisciplinary, and he often explains his theory using a dualism between the psychological characteristics of individuals on the one hand and the social structures on the other ${ }^{3}$. Keynes still has in mind in the GT the market model when analyzing the economy despite the fact that it is an endogenously unstable market characterized by agents who are not purely rational, by strong uncertainty and by assets with different degrees of liquidity. Of course, in terms of economic policy, this view of markets as endogenously and structurally unstable is very different from the laissez faire friendly policies of traditional neoclassical analyses, which do not presuppose the inherent instability of the market system.

In other words, Keynes introduces novelties in his analyses of markets: they are permeated by fundamental uncertainty, and this corresponds to the existence of different assets with different degrees of liquidity. Liquidity, for its turn, is necessary because there are different motives other than rational self-interest behind people's cognitive architecture. These motives are not reducible to preferences relating to risk, but are based on intuition, instincts and animal spirits.

That Keynes is still analyzing the economy in terms of markets in an interdisciplinary way can also be defended using the conclusions of GT's chapter 24: when the economy has reached full-employment, it can function along the lines proposed by the "classical school": if the weight of arguments upholding conventions is stable so that uncertainty is momentarily controlled, then agents can increasingly make decisions based on self-interested rationality (rather than intuition, instincts and animal spirits). In other words, it is possible to say that Keynes uses insights from other disciplines of his time (like psychology and psychoanalysis) or the contributions of heretic authors (like Hobson, Gesell and Marx) but he still

\footnotetext{
${ }^{3}$ See, for example, chapters 8 and 9 of the GT: the objective and subjective factors of the propensity to consume.

${ }^{4}$ Many commentators see an inconsistency between Keynes revolutionary content of the GT and statements (mainly in chapter 24 of the GT) that point to a reconciliation between Keynes's ideas and the neoclassical school. For a recent discussion of the subject (arguing that there is no inconsistency) see O’Donnell (2020).
} 
analyses the economy in terms of agents making decisions in markets, much like North does.

For example, right after he talks about how liquidity depends on social practices and institutions at the end of chapter 17 of the GT, he adds that "the order of preference in the minds of owners of wealth in which (...) they express their feelings about liquidity is, however, definite and is all we require for our analysis". In chapter 24 of the GT Keynes stands behind individualism, "if it can be purged of its defects and its abuses" because it "is the best safeguard of personal liberty in the sense that, compared with any other system, it greatly widens the field for the exercise of personal choice". Finally, Brady (2004, p.37) points out the fact that Keynes believed that "a ranking of alternatives, ordinal measurement, was the appropriate tool to use. Such a ranking complemented Keynes's 'interval estimate' approach [in the TP]"5.

Table 1- Synthetic framework of the argument

\begin{tabular}{|c|c|c|c|}
\hline & Veblen & Keynes & North \\
\hline $\begin{array}{l}\text { 1. Individual } \\
\text { action in the } \\
\text { social world }\end{array}$ & $\begin{array}{l}\text { Action based on } \\
\text { instinct-institutions }\end{array}$ & $\begin{array}{l}\text { Action based on four } \\
\text { moving mechanisms } \\
\text { (instincts, intuition, } \\
\text { animal spirits and } \\
\text { rationality) }\end{array}$ & $\begin{array}{l}\text { Action based on rationality- } \\
\text { institutions }\end{array}$ \\
\hline $\begin{array}{l}\text { 2. Efficient } \\
\text { Action }\end{array}$ & $\begin{array}{l}\text { An efficient action } \\
\text { obeys the principle } \\
\text { of social } \\
\text { conformity (actions } \\
\text { conform to habits } \\
\text { of thought) }\end{array}$ & $\begin{array}{l}\text { Actions within the market } \\
\text { in an uncertain world } \\
\text { usually and endogenously } \\
\text { lead to suboptimal } \\
\text { (inefficient) results in } \\
\text { terms of Pareto }\end{array}$ & $\begin{array}{l}\text { Efficient actions are } \\
\text { adaptive: incentive } \\
\text { structures lead to a set of } \\
\text { institutions which diminish } \\
\text { uncertainty when there is an } \\
\text { external shock to the } \\
\text { economy }\end{array}$ \\
\hline
\end{tabular}

\footnotetext{
${ }^{5}$ There are examples of Keynes mentioning the influence of uncertainty on the choice individuals make between present consumption and investment in capital goods (section VI of chapter 12). The beginning of chapter 16 shows Keynes dealing with a trade-off between present and future consumption, showing that he effectively used the framework of rational choice when strong uncertainty was not present.
} 


\begin{tabular}{|c|c|c|c|}
\hline $\begin{array}{l}\text { 3. Uncertainty } \\
\text { and } \\
\text { Ergodicity }\end{array}$ & $\begin{array}{l}\text { neither uncertainty } \\
\text { nor ergodicity are } \\
\text { treated directly }\end{array}$ & $\begin{array}{l}\text { uncertainty is directly } \\
\text { treated in the analysis; } \\
\text { socioeconomic world can } \\
\text { be understood as complex } \\
\text { and non-ergodic }\end{array}$ & $\begin{array}{l}\text { uncertainty is directly } \\
\text { included in the analysis; } \\
\text { socioeconomic world is } \\
\text { non-ergodic }\end{array}$ \\
\hline 4. Institutions & $\begin{array}{l}\text { Institutions are } \\
\text { habits of thought, } \\
\text { ways of doing and } \\
\text { thinking in the } \\
\text { social world }\end{array}$ & $\begin{array}{l}\text { (i) institutions are constrain } \\
\text { and mechanisms that may } \\
\text { action cannot be fully ration }\end{array}$ & $\begin{array}{l}\text { s to individual rational choice } \\
\text { educe uncertainty, so that (ii) } \\
\text { aal in an uncertain world. }\end{array}$ \\
\hline & \multicolumn{2}{|c|}{$\begin{array}{l}\text { (i) Institutions evolve by an interactive } \\
\text { (evolutionary) process of decision making; as a } \\
\text { consequence (ii) social reality does not obey any } \\
\text { single law of movement. }\end{array}$} & $\begin{array}{l}\text { Institutions are formal and } \\
\text { informal rules of the game } \\
\text { in socioeconomic } \\
\text { interactions }\end{array}$ \\
\hline
\end{tabular}

Source: Authors' own elaboration.

\section{Conclusion}

Throughout the article we highlighted some aspects of Veblen, Keynes and North's theoretical frameworks that enabled us to build the table of the previous section. In this table, we showed four elements that provided a key to understanding the relation between Keynes and Institutional Economics. The choice of Veblen and North allowed us to observe the adherence of Keynes's ideas to the two main branches of Institutional Economics, Veblen's old institutionalism and North's new one.

In a more transdisciplinary approach, Veblen pictured the social world as inhabited by individuals driven by instincts who, in their actions, thoughts and interactions, ended up creating habits of thought or institutions. Thus, the author held an instinct-institutions approach. Veblen was not worried about disciplinary boundaries (which were not clear at that time), and in some sense this gave him freedom concerning the theoretical instruments he could use and develop. He was against the idea of a calculative hedonistic man implied in the Jevonian strand of pure economic theory. 
Unlike Veblen, North does not reject the neoclassical tradition but points out the need to relax some of its hypotheses. The hypothesis of bounded rational individuals and new theoretical elements (like institutions and history) are welcome into the neoclassical research program. Therefore, North was engaged in a rationality-institutions approach. North's research agenda was developed in a different academic environment, in which Economics was already a separate discipline and defined its theoretical instruments inspired by the marginalist tradition. The implications for North's theoretical proposal are that, while he develops an interdisciplinary dialogue with other social sciences, the unrestricted adherence to a theory of rational choice ends up limiting the extent of his contributions beyond the neoclassical tradition.

Let us now analyze the fourth line (4. "Institutions") of Table 1 to explain how Keynes stands, in our view, between the Old Institutionalism of Veblen and the New Institutionalism of North, both in epistemological and ontological terms.

Keeping in mind that we understand epistemology in terms of inter- or transdisciplinarity, it is possible to say that Keynes is closer to North in this regard because he analyzes the economy in the GT in terms of market interactions which can be studied, in principle, separately from other disciplines. However, the frontiers of economics must be open to the influence of psychological factors (in the form of intuitions and animal spirits), power and conventions. This move marks a modification from Marshall's proposed frontiers to economics: with Keynes, economics will incorporate the concepts of uncertainty, liquidity and conventions. Unlike Veblen, Keynes kept some ideas of the marginalist tradition (mainly coming from Marshall), but he did not fully embrace the rational choice apparatus, like North. This is why it is possible to understand Keynes's conventions as mechanisms to reduce uncertainty in the market and as a way to cope with the limits of rational choice, much like North does.

But that is not the whole story. From an ontological perspective, our two authors agree that the world is non-ergodic and fundamentally uncertain. However, human action in such a world is analyzed in different ways: whereas for North rational action is the basis of all socioeconomic decisions, for Keynes and Veblen the 
role of instincts in the decision-making process must be recognized. Keynes, moreover, adds intuition and animal spirits to his conception of human action (besides, of course, rational action). This complex cognitive architecture makes Keynes closer to Veblen, since both of them can be understood as defending a conception of interactive-evolutionary process of decision-making and an idea of an evolving socioeconomic reality that does not obey any single law of movement.

As a result, Keynes stands between the institutionalism of North and Veblen. We hope to have shown that it is possible to build a future Keynesian institutionalism based on the idea that socioeconomic reality is complex, non-ergodic and fundamentally uncertain. However, this is just a first step in our investigation, since there are incompatibilities among our authors regarding the study of human action in such a reality. A possible future line of research is to compare how other institutionalists (like Coase e Williamson) portray the results of market interaction as not systematically the most efficient (Herscovici, 2012), along the lines of Keynes's results. In Williamson, for example, Keynesian uncertainty can also be related to incomplete contracts, and the notion of liquidity can be linked to the specificity of different assets. But this is the theme of a future paper.

\section{References}

Barnett, V. (2015), "Keynes and the psychology of economic behavior: From stout and sully to the general theory", History of Political Economy, 47(2), p. 30733. doi: 10.1215/00182702-2884345

Barnett, V. (2017a), "Veblen's two types of instinct and the cognitive foundations of evolutionary-institutional economics", Journal of Economic Issues, 51(22), p.541-562. doi: 10.1080/00213624.2017.1321453

Barnett, V. (2017b), "Keynes, animal spirits, and instinct: Reason plus intuition is better than rational", Journal of the History of Economic Thought, 39(3), P.381-399. doi: 10.1017/S1053837216000274

Brady, M E. J. M. (2004), “Keynes's theory of decision making, induction and analogy: The role of interval valued probability in his approach". New York: XLibris. 
Cardoso, F. G.; Lima, G. T. (2008), "A concepção de Keynes do sistema econômico como um todo orgânico complexo", Economia e Sociedade, 17(3), p. 359-381. doi: 10.1590/S0104-06182008000300001

Coase, Ronald. (1937), "The Nature of the Firm". Economica, (November 1937), p. 386-495.

Davis, J. B. J. M. (1997), "Keynes on history and conventions". In: Harcourt, G.; Riach, P., A second edition of the general theory. New York: Routledge.

Dequech, D. (2011), "Financial conventions in Keynes's theory: The stock exchange", Journal of Post-Keynesian Economics, 33(3), p. 469-490. doi: 10.2753/PKE0160-3477330304

Desroches, C. T.; Rutherford, M. (2008), "The Institutional Reaction to Keynesian Economics", Journal of the History of Economic Thought, 30(1), p.29-48. doi: 10.1017/S1042771608000033

Herscovici, A. (2012), "Informação, Conhecimento e Direitos de Propriedade Intelectual: os limites dos mecanismos de mercado e das modalidades de negociação privada", Economia e Sociedade, 21(3), p.667-694. doi: 10.1590/S0104-06182012000300008

Hodgson, G. (1993), "Institutional economics: Surveying the 'old' and 'new'. Metronomica, 44(1), p.1-28. doi: 10.1111/j.1467-999X.1993.tb00786.x

Keller, R. R. (1983) "Keynes and institutional economics: compatibility or complementarity?" Journal of Economic Issues. XVII(4), December. doi: 10.1080/00213624.1983.11504189

Keynes, J.M. (2008 [1921]), "a treatise on probability”. New York: BN Publishing.

Keynes, J. M (1926). "Obituary of F. Y. Edgeworth". Economic Journal. 36(141) (March 1926), pp. 140-158.

Keynes, J.M. (1936), "The general theory of employment, interest and money". Available at https://cas2.umkc.edu/economics/people/facultypages/kregel/courses/econ6 45/winter2011/generaltheory.pdf, Accessed on June 16th, 2019. 
Keynes, J.M. "Letter to Roy Harrod, dated July, 4th, 1938". Available at http://economia.unipv.it/harrod/edition/editionstuff/rfh.346.htm\#23502, Accessed on June 16th, 2019.

Marshall, A. (1890), "Principles of economics: An introductory volume". Available at https://www.marxists.org/reference/subject/economics/marshall/, Acessed on May 25th, 2020.

Mouhammed, A. D. (1999), "Veblen and Keynes", International Journal of Politics, Culture and Society, 13(2), p.169-186. doi: 10.1023/A:1022971927320

North, D. (1990), "Institutions, institutional change and economic performance". Cambridge: Cambridge University Press.

North, D. (1993), "What do we mean by rationality?", Public Choice (1986-1998), 77(1), p.159-162. Doi: 10.1007/978-94-017-3402-8_16

North, D. (2005), Understanding the Process of Economic Change. Princeton: Princeton University Press.

O'Donnell, R. (2019). Some misunderstood aspects of the final chapter of Keynes's general theory. Review of Political Economy, 31(4), 509-527. doi: 10.1080/09538259.2020.1751473.

Peterson, W. C. (1977), "Institutionalism, Keynes and the real world", Nebraska Journal of Economics and Business, 16(3), p.201-221. doi: 10.1080/00213624.1977.11503432

Polanyi, K. (1944[2000]), A grande transformação: as origens de nossa época. Rio de Janeiro: Campus.

Robbins, L. (1932), An essay on the nature and significance of economic science. London: Macmillan \& Co. Limited.

Rotheim, R. J. (1989), "Organicism and the role of the individual in Keynes's thought", Journal of Post Keynesian Economics. 12(2), p.316-326. doi: 10.1080/01603477.1989.11489801 
Runde, J. (1990), "Keynesian uncertainty and the weight of arguments", Economics and Philosophy, 6(2), p.275-292. doi: 10.1017/S0266267100001255

Sembert, M. (1991), "Advancing the social sciences through the interdisciplinary enterprise", The Social Science Journal, 28(1), p. 1-14. doi: 10.1016/03623319(91)90040-B

Setterfield, M. (1999), "Expectations, path dependence and effective demand: A macroeconomic model along Keynesian lines", Journal of Post-Keynesian Economics, 21(3), p.479-501. doi: 10.1080/01603477.1999.11490209.

Skidelski, R. (2005), John Maynard Keynes (1883-1946): Economist, philosopher, statesman. New York: Penguin Group.

Skidelski, R. (2010), John Maynard Keynes: A very short introduction. Oxford: Oxford University Press.

Thabet, S. (2008), "Keynes and commons: Parallel stories, crossed destinies", L'Economie Politique, 38(2), p.77-100. doi: 10.3917/leco.038.0077

Veblen, T. (1899), "The theory of the leisure class". Available at http://moglen.law.columbia.edu/LCS/theoryleisureclass.pdf, Access on May 10th, 2019.

Whalen, C. J. (2012) "Post-Keynesian institutionalism after the great recession". Working Paper 724 of the Levy Institute. Available at http://www.levyinstitute.org/pubs/wp_724.pdf. Access on May 25th 2020.

Williamson, Oliver. (1985), "Transaction cost economics". In: Williamson, Oliver. The economic institution of capitalism. London: The Free Press, p. 15-42.

Wray, L. R. (2007), “Veblen's theory of business enterprise and Keynes's monetary theory of production", Journal of Economic Issues, 41(2). doi: 10.1080/00213624.2007.11507052 